\title{
Arginine Analogues: Effect on Growth and on the First Two Enzymes of the Arginine Pathway in Pseudomonas aeruginosa
}

\author{
By T. LEISINGER, CHRISTINE O'SULLIVAN AND D. HAAS \\ Mikrobiologisches Institut, Eidgenössische Technische Hochschule, \\ CH-8006 Zürich, Switzerland
}

(Received I I February 1974; revised I3 May 1974)

\section{SUMMARY}

The effect of 14 arginine analogues on the growth of Pseudomonas aeruginosa in a liquid mineral medium with either L-glutamate or L-ornithine as the sole carbon and nitrogen source was investigated. Two analogues, L-indospicine and L-arginine hydroxamate, inhibited growth markedly. The former was most effective in the ornithine medium and the latter only in the glutamate medium.

The inhibition by arginine analogues of the first two enzymes of the arginine pathway, $N$-acetylglutamate synthetase and $N$-acetylglutamate 5-phosphotransferase, was studied. It was found that inhibition of these two feedback-sensitive enzymes did not correlate with inhibition of growth. $O$-(L-norvalyl-5)-isourea, which was a rather weak inhibitor of growth, was at least three times more active as an inhibitor of the enzymes than L-indospicine and L-arginine hydroxamate. These two analogues were about ten times less effective than L-arginine, the strongest inhibitor of both enzymes.

\section{INTRODUCTION}

Metabolite analogues have been used successfully for the isolation of regulatory mutants in studies on the control of biosynthetic pathways in Enterobacteriaceae. In Pseudomonas aeruginosa the limited availability of effective analogues (Holloway, 1969; Kay \& Gronlund, 1969) has impeded the elucidation of control mechanisms in its metabolism. In an effort to increase its sensitivity to metabolite analogues, Calhoun \& Jensen (1972) found that $p$-aminophenylalanine and $\beta$-2-thienylalanine (a tyrosine and a phenylalanine analogue, respectively) inhibited growth on media with fructose but not with glucose as the carbon source. They suggested that the carbon flow through the aromatic amino acid biosynthetic sequence is relatively low on the fructose medium, resulting in a limitation of aromatic amino acids or their precursors and thus increasing the sensitivity to analogues.

We report the inhibitory action of several analogues and derivatives of arginine on $P$. aeruginosa. In this organism, as well as in all other bacteria studied, biosynthesis proceeds from glutamate via ornithine and citrulline in eight enzymic steps to arginine. Ornithine, a key intermediate in this pathway, is formed by transacetylation of glutamate and $N^{2}$ acetylornithine (Isaac \& Holloway, 1972), in contrast to the situation in the Enterobacteriaceae (Vogel \& Bonner, 1956; Udaka, I966) where it is produced by deacylation of $N^{2}-$ acetylornithine. Arginine auxotrophs of P.aeruginosa form seven transduction groups (Feary, Williams, Calhoun \& Walker, 1969), which indicates the absence of clustering among the structural genes of the arginine pathway. Analysis of the control mechanisms in the arginine pathway is complicated by the existence of different catabolic pathways for arginine and by 
the lack of regulatory mutants. So far it has been shown that the levels of three out of eight arginine biosynthetic enzymes tested respond to changes in the extracellular arginine supply; $\mathrm{N}$-acetylglutamic 5-semialdehyde dehydrogenase (Voellmy \& Leisinger, 1972) and orthithine carbamoyltransferase (Isaac \& Holloway, 1972) are repressed, whereas $N^{2}$-acetylornithine 5-aminotransferase is induced by arginine (Voellmy \& Leisinger, 1972). $\mathrm{N}$-acetylglutamate synthetase and $N$-acetylglutamate 5-phosphotransferase, the first two enzymes of arginine synthesis, are regulated by feedback inhibition (Haas, Kurer \& Leisinger, 1972; Leisinger, Haas \& Hegarty, 1972). This double control of arginine synthesis by end-product inhibition of two consecutive enzymes has been demonstrated only in $P$. aeruginosa but might occur also in other micro-organisms with the transacetylase modification of the pathway. In an effort to understand the criteria that make arginine analogues potent inhibitors of growth, we have studied their effect on the two feedback-sensitive enzymes of arginine biosynthesis. Some preliminary data have been published previously (Haas \& Leisinger, 1972).

\section{METHODS}

Organisms. All experiments were performed with the wild-type strain Pseudomonas aeruginosa PAOI (Holloway, 1969).

Media. Growth experiments were made on minimal medium P (Leisinger et al. 1972) with $20 \mathrm{mM}-\mathrm{L}$-glutamate or $20 \mathrm{mM}-\mathrm{L}$-ornithine as the carbon and nitrogen source. Inoculum cultures were prepared on medium E (Vogel \& Bonner, 1956).

Growth tests. An overnight culture of strain PAOI grown on medium $\mathrm{E}$ was washed in saline $(0.85 \% \mathrm{NaCl})$ and used to inoculate $($ at $\mathrm{I} \%, \mathrm{v} / \mathrm{v})$ test tubes containing $5 \mathrm{ml}$ of medium $\mathrm{P}$ with L-glutamate or L-ornithine as indicated. For the experiment described in Table $\mathrm{I}$ the analogues were added at the time of inoculation. The tubes were incubated at $37^{\circ} \mathrm{C}$ on a rotatory shaker ( $300 \mathrm{rev} . / \mathrm{min}$ ) and growth was followed by measuring the absorbance at $546 \mathrm{~nm}$ in an Eppendorf photometer.

Purification and assay of feedback-sensitive enzymes. The partial purification and the assay of $\mathrm{N}$-acetylglutamate synthetase (acetyl-CoA: L-glutamate $\mathrm{N}$-acetyltransferase, EC. 2.3.I.I) have been described previously (Haas et al. 1972). The incubation mixture routinely contained $7 \mathrm{~mm}$-amino-oxyacetic acid, an inhibitor of pyridoxal phosphatedependent enzymes (Wilson \& Holden, 1969) such as arginine decarboxylase.

$\mathrm{N}$-acetylglutamate 5-phosphotranferase (ATP: $\mathrm{N}$-acetyl-L-glutamate 5-phosphotransferase, EC. 2.7.2.8) purified to near homogeneity from PAOI (D. Haas and T. Leisinger, unpublished) was assayed by the hydroxamate- $\mathrm{FeCl}_{3}$ method unless otherwise stated. Enzyme $(0.3 \mu \mathrm{g})$ was incubated at $37^{\circ} \mathrm{C}$ in $0.5 \mathrm{ml}$ of a reaction mixture containing: $\mathrm{NH}_{2^{-}}$ $\mathrm{OH} \cdot \mathrm{HCl}, 200 \mu \mathrm{mol}$; tris, $200 \mu \mathrm{mol}$; ATP (disodium salt), $5 \mu \mathrm{mol} ; \mathrm{MgCl}_{2}$, $10 \mu \mathrm{mol} ; N$ acetyl-L-glutamic acid (neutralized with $\mathrm{KOH}$ ), $20 \mu \mathrm{mol}$. The reaction mixture was adjusted to $\mathrm{pH} 7 \cdot 2$ with $\mathrm{NaOH}$ at $25{ }^{\circ} \mathrm{C}$. After Io to $20 \mathrm{~min}$ incubation the reaction was stopped by addition of $0.5 \mathrm{ml}$ of a solution containing $8 \%(\mathrm{w} / \mathrm{v})$ trichloroacetic acid and $5 \%(\mathrm{v} / \mathrm{v})$ $\mathrm{FeCl}_{3} .6 \mathrm{H}_{2} \mathrm{O}$ in $0.3 \mathrm{M}-\mathrm{HCl}$. The absorbance of the hydroxamate formed was read at $540 \mathrm{~nm}$ (Lipmann \& Tuttle, I945).

Inhibition of $\mathrm{N}$-acetylglutamate 5-phosphotransferase by L-arginine hydroxamate, L-arginine methyl ester and L-2-chloro-5-guanidinovaleric acid was measured by the method of Vogel \& McLellan (1970), modified as follows: in a total volume of $200 \mu \mathrm{l}$, the reaction mixture contained ATP (disodium salt), $2 \cdot 0 \mu \mathrm{mol} ; \mathrm{MgCl}_{2}, 4.0 \mu \mathrm{mol} ; N$-acetyl-L-glutamic acid (neutralized with $\mathrm{KOH}$ ), $8.0 \mu \mathrm{mol}$; 2-phosphoenolpyruvic acid (trisodium salt), $\mathrm{I} \cdot 0 \mu \mathrm{mol}$; potassium phosphate buffer (final $\mathrm{pH} 6.8$ at $25^{\circ} \mathrm{C}$ ), $25.0 \mu \mathrm{mol}$; pyruvate kinase, 
Table I. Effect of arginine analogues on the growth of Pseudomonas aeruginosa PAOI

The growth tests were performed in duplicate as described in Methods.

$\begin{array}{lcc} & \overbrace{\text { On medium }}^{\begin{array}{c}\text { P with } \\ \text { L-glutamate } \\ (20 \mathrm{mM})\end{array}} & \begin{array}{c}\text { On medium } \\ \text { P with } \\ \text { L-ornithine } \\ \text { Inhibitor (2 mM) }\end{array} \\ \text { None } & 100 \dagger & 100 \ddagger \\ \text { L-Indospicine } & 42 & 12 \\ \text { L-Arginine hydroxamate } & 25 & 137 \\ \text { O-(L-norvalyl-5)-isourea } & 38 & 60 \\ \text { L-Canavanine } & 53 & 51 \\ \text { L-2-Amino-4-guanidinobutyric acid } & 51 & 77 \\ \text { L-Homoarginine } & 67 & 80 \\ \text { L-2-Chloro-5-guanidinovaleric acid } & 85 & 73 \\ \text { L- } N^{5} \text {-(I-iminoethyl)-ornithine } & 90 & 73\end{array}$

* Growth rates in the presence of inhibitors were determined in several independent experiments and are expressed relative to the growth rate of an uninhibited culture included as a reference in each experiment. $\dagger$ Growth rate constant $=0.590 \pm 0.109 \mathrm{~h}^{-1}$ (mean \pm S.D. $)$.

$\ddagger$ Growth rate constant $=0.168 \pm 0.035 \mathrm{~h}^{-1}$ (mean \pm S.D.).

$7 \cdot 5$ units. The reaction was started by the addition of $0.13 \mu \mathrm{g}$ purified enzyme to this mixture and incubation was made at $37^{\circ} \mathrm{C}$ for $15 \mathrm{~min}$. To stop the enzymic reaction $0.2 \mathrm{ml} 2,4^{-}$ dinitrophenylhydrazine solution ( $5 \mathrm{mM}$ in $4 \mathrm{M}-\mathrm{HCl}$ ) was added. After $5 \mathrm{~min}$ at room temperature each tube received $2.0 \mathrm{ml} \mathrm{I} \cdot 5 \mathrm{M}-\mathrm{NaOH}$ and the amount of hydrazone formed was determined by reading the absorbance at $546 \mathrm{~nm}$. When assayed by this procedure our enzyme preparations were about twice as active as when measured with the hydroxamate assay. The relative inhibition of the enzyme by arginine was identical in both assays.

Chemicals. Amino acids including $N$-acetyl-L-glutamic acid were purchased from Fluka (Buchs, Switzerland); D-arginine-HCl, L-canavanine sulphate, L-2-amino-4-guanidinobutyric acid, and 2-phosphoenolpyruvic acid (trisodium salt) from Calbiochem; L-arginine hydroxamate, L-argininic acid, and ATP (disodium salt) from Sigma; $\mathrm{N}$-acetyl-L-arginine and Larginine methyl ester.2 $\mathrm{HCl}$ from Nutritional Biochemicals Corp. (Cleveland, Ohio, U.S.A.); L-homocitrulline from Schuchardt (München, Germany); L-5-guanidinovaleric acid from Cyclo (Los Angeles, California); and pyruvate kinase (rabbit muscle) from Boehringer Mannheim GmbH (Mannheim, Germany). L-2-Chloro-5-guanidinovaleric acid was prepared according to Hamilton \& Ortiz (1955). L-Indospicine $\cdot \mathrm{HCl} . \mathrm{H}_{2} \mathrm{O}$ (Hegarty \& Pound, 1968) was received from Dr M. P. Hegarty (C.S.I.R.O. Division of Tropical Pastures, Cunningham Laboratory, St Lucia, Queensland, Australia). L- $N^{5}$-(I-iminoethyl)-ornithine (Scannell et al. 1972) was kindly supplied by Dr J. P. Scannell (Hoffmann-La Roche Inc., Nutley, New Jersey, U.S.A.) and $O$-(L-norvalyl-5)-isourea (König, Kneifel, Bayer, Müller \& Zähner, 1973) by Dr G. Müller and Professor H. Zähner (Institut für Mikrobiologie der Universität Tübingen, Germany).

\section{RESULTS}

Fourteen arginine analogues were screened for growth inhibition of strain PAOI. Eight were found to be effective and are listed in Table I. Those showing no inhibitory effects were L-argininic acid, L-5-guanidinovaleric acid, D-arginine, L-homocitrulline, L-arginine methyl ester, and $\mathrm{N}$-acetyl-L-arginine. The effect of analogues on growth was examined 


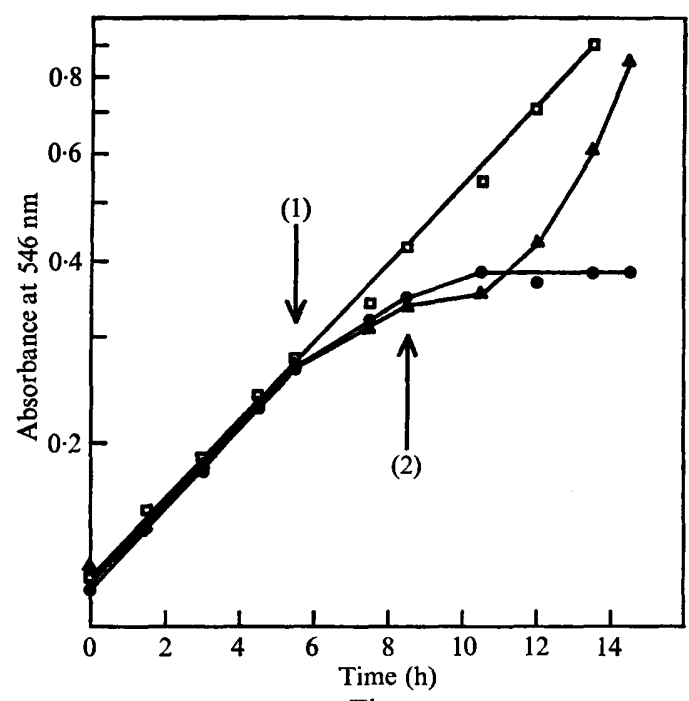

Fig. I

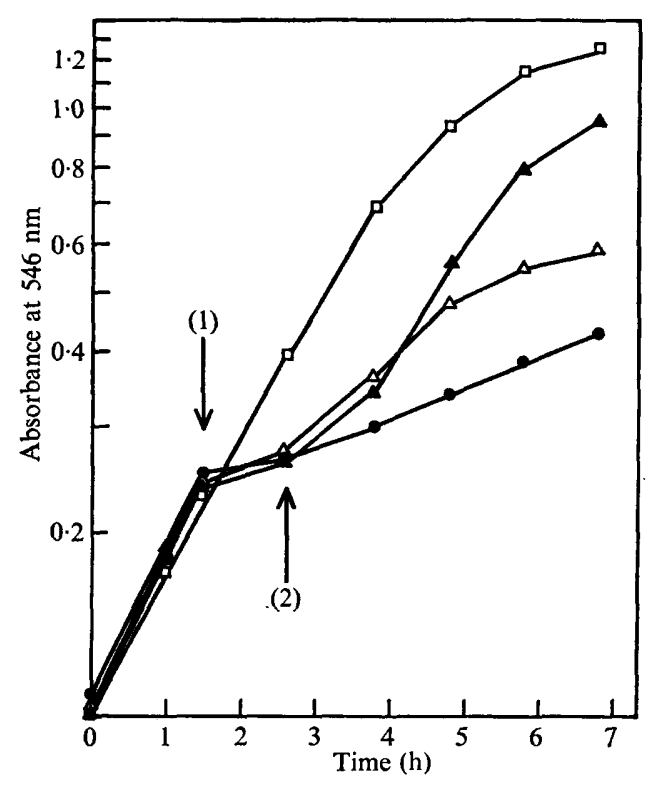

Fig. 2

Fig. I. Growth inhibition of $\boldsymbol{P}$. aeruginosa PAOI by indospicine on medium $\mathbf{P}$ with 20 mM-ornithine. $\square$ Control; 0 addition of indospicine $(2 \mathrm{mM})$ at $(1) ; \Delta$, addition of indospicine $(2 \mathrm{mM})$ at $(\mathrm{I})$ and addition of arginine (20 $\mathrm{mm})$ at (2).

Fig. 2. Growth inhibition of $P$. aeruginosa PAOI by arginine hydroxamate on medium $P$ with $20 \mathrm{~mm}$ glutamate. $\square$, Control; $\Theta$, addition of arginine hydroxamate $(2 \mathrm{mM})$ at( $(1) ; \triangle$, addition of arginine hydroxamate $(2 \mathrm{mM})$ at (I) and addition of arginine $(0.2 \mathrm{mM})$ at $(2) ; \Delta$, addition of arginine hydroxamate ( $2 \mathrm{mM})$ at (I) and addition of arginine (2 $\mathrm{mM})$ at (2).

on medium P with $20 \mathrm{mM}$-glutamate (resulting in a mass-doubling time of $\mathrm{I} \cdot \mathrm{O}$ to $\mathrm{I} \cdot 3 \mathrm{~h}$ ) as well as on medium $\mathbf{P}$ with $20 \mathrm{~mm}$-ornithine, which supports growth at a lower rate (doubling time 3 to $5 \mathrm{~h}$ ). Analogue concentrations of $2 \mathrm{~mm}$ and $20 \mathrm{~mm}$ gave similar results. The growth tests showed (Table I) that indospicine and arginine hydroxamate were the most effective inhibitors. Inhibition by indospicine was best (about eightfold decrease in growth rate) on the ornithine medium, whereas arginine hydroxamate caused an approximately fourfold lowering of the growth rate on the glutamate medium but stimulated growth on the ornithine medium. Although the other compounds listed in Table I had some growth inhibitory effect (up to a threefold decrease of the growth rate), we considered them not sufficiently potent to be of use for the isolation of analogue-resistant mutants. This assumption was confirmed in the case of $O$-(L-norvalyl-5)-isourea which was completely ineffective as a growth inhibitor of strain PAOr cultivated on solid medium P with $20 \mathrm{mM}$-glutamate. Indospicine and arginine hydroxamate on the other hand were good inhibitors of growth on solid media and have been successfully used for the isolation of resistant mutants (Leisinger, O'Sullivan and Haas, unpublished data). All arginine analogues which were not growth inhibitory increased the growth rate of PAOI on the ornithine medium and had no effect on its growth on the glutamate medium. This indicates that they were taken up and catabolized by $P$. aeruginosa.

Liquid medium $P$ supplemented with ammonium sulphate as the nitrogen source and fructose as the carbon source did not enhance the sensitivity of $P$. aeruginosa to canavanine and arginine hydroxamate. In this medium, the increase of doubling time was twofold with 2 mM-canavanine and threefold with 2 mM-arginine hydroxamate. Thus, although growth 


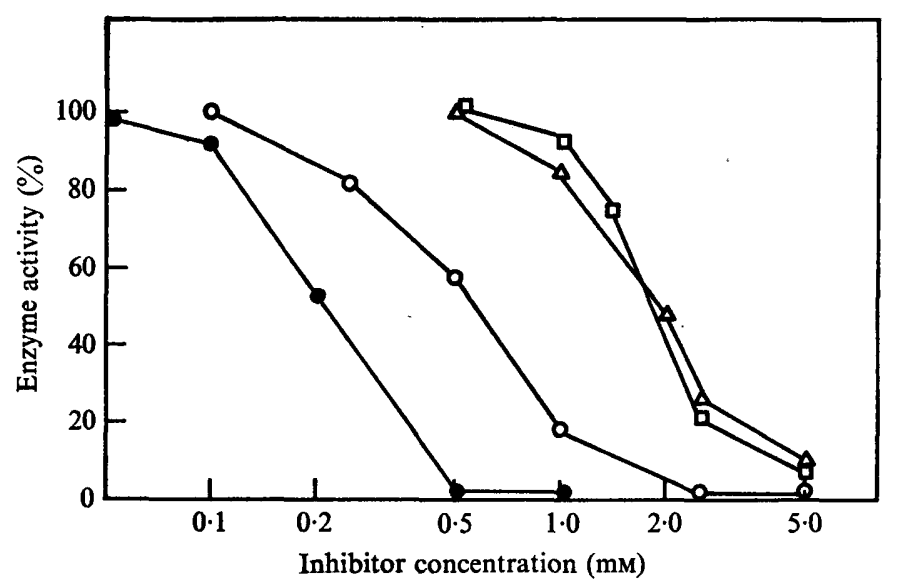

Fig. 3. Inhibition of $\mathrm{N}$-acetylglutamate synthetase by arginine analogues. $\mathrm{O}, \mathrm{L}$-Arginine; $O, O$-(L-norvalyl-5-)isourea; $\Delta$, L-arginine hydroxamate; $\square$, L-indospicine.

in the fructose medium was about three times slower than in medium $P$ with glutamate, the inhibition by the two analogues remained essentially unchanged (cf. Table I). The use of fructose as the carbon source apparently did not lead to a limitation of arginine or its precursors. In contrast, Calhoun \& Jensen (1972), employing a similar fructose medium, observed that $P$. aeruginosa became relatively sensitive to analogues of tyrosine, phenylalanine and tryptophan.

The effect of indospicine and arginine hydroxamate was studied in more detail. Figure I shows the inhibition of growth of PAOI upon addition of indospicine at $2 \mathrm{~mm}$ and the reversal of this inhibition by $20 \mathrm{~mm}$-arginine. Addition of $2 \mathrm{~mm}$-arginine resulted in only a partial relief from inhibition. Figure 2 illustrates the antagonistic effect of arginine on the growth inhibition by arginine hydroxamate. Arginine at $0.2 \mathrm{~mm}$ relieved the inhibition partially and at $2 \mathrm{~mm}$ overcame it completely. In the case of arginine hydroxamate the growth inhibition was also relieved by $2 \mathrm{mM}$-ornithine or by $20 \mathrm{~mm}$-lysine (not shown). In contrast, these two amino acids were ineffective as antagonists of indospicine.

There are several conceivable ways in which indospicine and arginine hydroxamate could act as antimetabolites. We chose to study their effect on purified preparations of the feedbacksensitive enzymes in the arginine pathway. Figure 3 shows the inhibition of an approximately eightfold purified preparation of $\mathrm{N}$-acetylglutamate synthetase (free of arginine deiminase) from strain PAOI by three analogues of arginine. $O$-norvalyl-isourea was a stronger inhibitor of the enzyme than arginine hydroxamate and indospicine but was a weaker inhibitor of growth. These three analogues inhibited the enzyme less efficiently than arginine. All the other arginine analogues with the exception of arginine methyl ester were tested at a concentration of $5 \mathrm{~mm}$ and found not to inhibit the enzyme.

The effect of some arginine analogues on a highly purified preparation of $N$-acetylglutamate 5-phosphotransferase is shown in Fig. 4. Again arginine was the most effective inhibitor followed by norvalyl-isourea, 2-amino-4-guanidinobutyric acid, arginine methyl ester, arginine hydroxamate and finally $N^{5}$-(I-iminoethyl)-ornithine. Indospicine and canavanine were similar to $N^{5}$-(I-iminoethyl)-ornithine (not shown in Fig. 4; cf. Leisinger et al. 1972). The remaining analogues were without effect on the phosphotransferase when tested at a concentration of $10 \mathrm{~mm}$. 


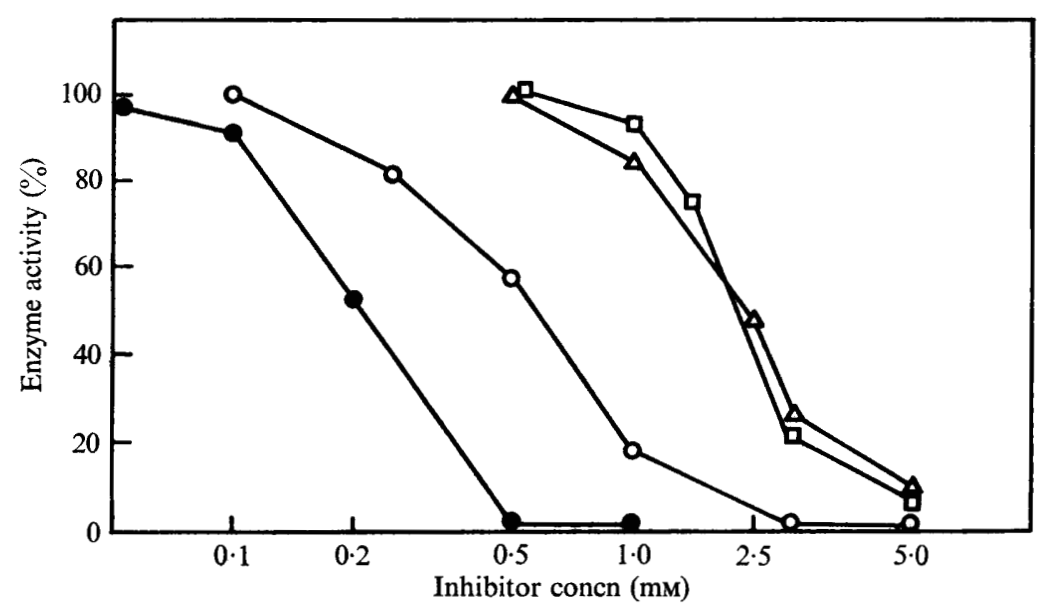

Fig. 4. Inhibition of $N$-acetylglutamate 5-phosphotransferase by arginine and analogues. L-Arginine; $\square, O$-(L-norvalyl-5)-isourea; $O$, L-arginine hydroxamate; $\square$, L-2-amino-4-guanidinobutyric acid; $\Delta$, L-arginine methyl ester; $\triangle$, L- $N^{5}$-(I-iminoethyl)-ornithine.

\section{DISCUSSION}

No single hypothesis explains the resistance of $P$. aeruginosa to analogues of metabolites. Possible causes for this resistance are: inefficient uptake of the analogues, lack of inhibition by analogues of the feedback-sensitive enzymes, inability of analogues to act as co-repressors, inefficacy of analogues as substrates or inhibitors of aminoacyl-tRNA synthetase, efficient degradation of analogues to non-toxic products (Fowden, Lewis \& Tristram, 1967; Nass, Poralla \& Zähner, I97I).

We have tested analogues and derivatives of arginine as growth inhibitors of $P$. aeruginosa. Only two compounds, indospicine and arginine hydroxamate, were sufficiently effective to permit isolation of resistant mutants. In both cases the extent of the inhibition depended strongly on the conditions of carbon flow in the organisms (TableI). The source of carbon and nitrogen had also a pronounced influence on the effect exerted by the remaining lesspotent inhibitors. This finding confirms that the nutritional environment determines the response to metabolite analogues to a considerable extent.

Our further experiments were directed towards the elucidation of the mode of action of the inhibitors. We examined whether potent inhibitors of growth were also effective against the two feedback-sensitive enzymes of the arginine pathway. Indospicine and arginine hydroxamate inhibited $N$-acetylglutamate synthetase and $N$-acetylglutamate 5-phosphotransferase. However, the inhibitor concentrations needed to inhibit these two enzymes were comparatively high. Indospicine was a more effective inhibitor of growth on the ornithine medium than on the glutamate medium (Table $\mathrm{I}$ ). When the organism is cultivated on ornithine, it is probably not dependent on the biosynthesis of this amino acid and therefore an interaction of indospicine with the first two enzymes of the pathway would not be responsible for the inhibition of growth. Presumably, indospicine causes its toxic effect by another mechanism, e.g. by acting at the level of formation of arginyl-tRNA. Some experiments with Escherichia coli support this speculation. In $E$. coli, indospicine is charged onto tRNA ${ }^{\mathrm{Arg}}$ and incorporated into protein (Leisinger et al. 1972). 
In the case of arginine hydroxamate, an effect on the feedback-sensitive enzymes in vivo cannot be ruled out $a$ priori as growth inhibition on a glutamate medium was strong, whereas on ornithine a stimulation was observed (Table I). Arginine hydroxamate has been used for the isolation of arginine-excreting mutants of Bacillus subtilis by Kisumi, Kato, Sugiura \& Chibata (1971). However, the site of action of arginine hydroxamate was not elucidated.

Norvalyl-isourea was approximately three times more potent an inhibitor of both feedbacksensitive enzymes than indospicine and arginine hydroxamate, but was less effective as a growth inhibitor than the two other analogues. In conclusion, the experiments with purified enzyme preparations showed that inhibition of growth and inhibition of the feedbacksensitive enzymes by arginine analogues were not correlated.

The inefficacy of most arginine analogues as growth inhibitors could be based on the specificity of transport. Except for arginine hydroxamate, we have no data to indicate the type of transport systems involved in the uptake of analogues. In Pseudomonas putida uptake of basic amino acids involves at least three different systems (Fan, Miller \& Rodwell, 1972). Assuming an analogy between transport mechanisms in $P$. aeruginosa and $P$. putida, the antagonistic effect of lysine or ornithine on the growth inhibition by arginine hydroxamate suggests that this analogue is transported predominantly by the general basic amino acid system.

Pseudomonads are able to catabolize a wide variety of compounds (Ornston, 1971). As illustrated by the following examples, this property is probably also important for the resistance of $P$. aeruginosa to analogues of arginine. $O$-(L-norvalyl-5)-isourea added to an exponentially growing culture caused a strong transient inhibition of growth in liquid culture (G. Müller, personal communication) but was completely inactive on organisms growing on solid media. Canavanine served as a source of nitrogen (Leisinger et al. 1972) and was oxidized by intact organisms (Kay \& Gronlund, 1969). Thus the build-up of an inhibitory intracellular concentration of this analogue may be prevented by degradative reactions. Indospicine on the other hand is probably resistant to degradation by the arginine dihydrolase pathway (Ramos, Stalon, Piérard \& Wiame, 1967) owing to its chemical structure.

We are most grateful to Drs M. P. Hegarty, G. Müller, J. P. Scannell and H. Zähner for samples of arginine analogues. The technical assistance of Vreni Weber is gratefully acknowledged. This work was supported by the Swiss National Foundation for Scientific Research (Project No. 3.717.72).

\section{REFERENCES}

Calhoun, D. H. \& Jensen, R. A. (1972). Significance of altered carbon flow in aromatic amino acid synthesis: an approach to the isolation of regulatory mutants in Pseudomonas aeruginosa. Journal of Bacteriology I09, 365-372.

FAN, C. L., MIller, C. L. \& Rodwell, V. W. (1972). Metabolism of basic amino acids in Pseudomonas putida. Transport of lysine, ornithine, and arginine. Journal of Biological Chemistry 247, 2283-2288.

Feary, T. W., Williams, B., Calhoun, D. H. \& Walker, T. A. (1969). An analysis of arginine requiring mutants in Pseudomonas aeruginosa. Genetics 62, 673-686.

Fowden, L., LewIS, D. \& TristraM, H. (1967). Toxic amino acids: their action as antimetabolites. Advances in Enzymology 29, 89-163.

HAAS, D., KURER, V. \& LeIsInGer, T. (1972). N-Acetylglutamate synthetase of Pseudomonas aeruginosa. An assay in vitro and feedback inhibition by arginine. European Journal of Biochemistry 3r, 290-295.

HAAS, D. \& LeISINGER, T. (1972). Inhibition of Pseudomonas aeruginosa by analogues of arginine. Journal of General Microbiology 73, xiii.

Hamuton, P. B. \& ORtiz, P. J. (1955). L-Argininic acid ( $\alpha$-hydroxy- $\delta$-guanidino- $n$-valeric acid). Biochemical Preparations 4, 76-79. 
Hegarty, M. P. \& Pound, A. W. (I968). Indospicine, a new hepatotoxic amino-acid from Indigofera spicata. Nature, London 217, 354-355.

Holloway, B. W. (1969). Genetics of Pseudomonas. Bacteriological Reviews 33, 419-443.

IsAaC, J. H. \& Holloway, B. W. (1972). Control of arginine biosynthesis in Pseudomonas aeruginosa. Journal of General Microbiology 73, 427-438.

KAY, W. W. \& Gronlund, A. F. (1969). Isolation of amino acid transport-negative mutants of Pseudomonas aeruginosa and cells with repressed transport activity. Journal of Bacteriology 98, I I6-123.

Kisumi, M., Kato, J., Sugiura, M. \& Chibata, I. (197I). Production of L-arginine by arginine hydroxamateresistant mutants of Bacillus subtilis. Applied Microbiology 22, 987-991.

KöNIG, W. A., KNeIFel, H., BAYer, E., Müller, G. \& ZäHNer, H. (1973). Metabolic products of microorganisms I 16. $O$-(L-norvalyl-5)-isourea, a new arginine antagonist. The Journal of Antibiotics 26, 44-50.

LeIsinger, T., HAAS, D. \& HegarTy, M. P. (1972). Indospicine as an arginine antagonist in Escherichia coli and Pseudomonas aeruginosa. Biochimica et biophysica acta 262, 214-219.

LipmanN, F. \& Tuttle, L. C. (1945). A specific micromethod for the determination of acyl phosphates. Journal of Biological Chemistry 159, 2 I-28.

Nass, G., Poralla, K. \& Z̈̈HNER, H. (1971). Biogenic amino acid antagonists. Naturwissenschaften 58, 603-6ro.

ORNSTON, L. N. (197I). Regulation of catabolic pathways in Pseudomonas. Bacteriological Reviews 35, 87-I I6.

Ramos, F., Stalon, V., Piérard, A. \& Wiame, J. M. (1967). The specialization of the two ornithine carbamoyltransferases of Pseudomonas. Biochimica et biophysica acta 139, 98-106.

Scannell, J. P., Ax, H. A., Pruess, D. L., Williams, T., Demny, T. C. \& Stempel, A. (1972). Antimetabolites produced by microorganisms. VI. L- $N^{5}$-(I-iminoethyl)-ornithine. The Journal of Antibiotics 25, I79-184.

UDAKA S. (1966). Pathway-specific pattern of control of arginine biosynthesis in bacteria. Journal of Bacteriology 91, 61 7-62I.

Voel.my, R. \& Leisinger, T. (1972). Regulation of enzyme synthesis in the arginine system of Pseudomonas aeruginosa. Journal of General Microbiology 73, xiii.

VoGEL, H. J. \& BoNNER, D. M. (1956). Acetylornithinase of Escherichia coli: partial purification and some properties. Journal of Biological Chemistry 218, 97-106.

Vogel, H. J. \& MCLellan, W. L. (1970). N-Acetyl- $\gamma$-glutamokinase (Escherichia coli). Methods in Enzymology, r7A pp. 25I-255.

Wilson, O. H. \& Holden, J. T. (1969). Arginine transport and metabolism in osmotically shocked and unshocked cells of Escherichia coli w. Journal of Biological Chemistry 244, 2737-2742. 